\title{
Effects of feeding increasing dietary levels of high oleic or regular sunflower or linseed oil on fatty acid profile of goat milk
}

\author{
A. L. Martínez Marín, ${ }^{*}$ P. Gómez-Cortés, $\dagger^{1}$ G. Gómez Castro, ${ }^{*} M$. Juárez, $†$ L. Pérez Alba, ${ }^{*}$ \\ M. Pérez Hernández, ${ }^{* 2}$ and M. A. de la Fuente† \\ *Departamento de Producción Animal (Universidad de Córdoba), Ctra. Madrid-Cádiz, s/n. Campus de Rabanales, 14014 Córdoba, Spain \\ †Instituto de Investigación en Ciencias de la Alimentación (CSIC-UAM), Nicolás Cabrera, 9. Universidad Autónoma de Madrid, 28049 Madrid, \\ Spain
}

\section{ABSTRACT}

In this work, the effects of increasing amounts of 3 plant oils in diets on the fatty acid (FA) profile of goat milk were studied. The study consisted of 3 experiments, one per oil tested (linseed oil, LO; high oleic sunflower oil, HOSFO; and regular sunflower oil, RSFO). The 3 experiments were conducted successively on 12 Malagueña goats, which were assigned at random to 1 of 4 treatments: $0,30,48$, and $66(\mathrm{H}) \mathrm{g}$ of added oil/d. A basal diet made of alfalfa hay and pelleted concentrate (33:67) was used in all of the experiments. For each animal, milk samples collected after $15 \mathrm{~d}$ on treatments were analyzed for fat, protein, lactose, and FA composition, whereas individual milk yield was measured the last $3 \mathrm{~d}$ of each experiment. Oil supplementation affected neither dry matter intake nor milk production traits. Increasing the oil supplementation decreased the content of saturated FA (especially 16:0) in milk fat and increased mono- and polyunsaturated FA in a linear manner. Vaccenic acid content linearly increased with the oil supplementation by 370,217 , and $634 \%$ to $5.32,2.66$, and $5.09 \mathrm{~g} / 100 \mathrm{~g}$ of total FA methyl esters with the $\mathrm{H}$ diet in LO, HOSFO, and RSFO experiments, respectively. Rumenic acid content linearly increased with LO and RSFO supplementation by 298 and $354 \%$ from 0.53 and $0.41 \mathrm{~g} / 100 \mathrm{~g}$ of total FA methyl esters with the $0 \mathrm{~g}$ of added oil/d diet. The content of trans-10-18:1 was not affected by LO supplementation but showed an increasing linear trend with HOSFO supplementation and linearly increased with RSFO supplementation. The ratio of n- 6 to n-3 polyunsaturated FA in milk fat was decreased by about $70 \%$ with the $\mathrm{H}$ diet in the $\mathrm{LO}$ experiment and it was increased by 54 and $82 \%$ with the $\mathrm{H}$ diet in the HOSFO and

\footnotetext{
Received February 24, 2011.

Accepted November 26, 2011.

${ }^{1}$ Present address: Division of Nutritional Sciences, Cornell University, Ithaca, NY 14853.

${ }^{2}$ Corresponding author: vn1pehem@uco.es
}

RSFO experiments. In conclusion, LO supplementation in this work seemed to be the most favorable alternative compared with HOSFO or RSFO supplementation. Key words: fatty acid, goat milk, rumenic acid, vaccenic acid, plant oil

\section{INTRODUCTION}

It is well known that the FA profile in milk and meat from ruminant animals can be modified with appropriate dietary fat sources to get products richer in specific FA (Collomb et al., 2006; Givens et al., 2006). Among such FA, n-3 FA, mostly represented by $\alpha$-linolenic acid in milk fat, are commonly found in very low quantities in dairy products. In contrast, cis( $\boldsymbol{c})-9$, $\operatorname{trans}(\boldsymbol{t})-11-18: 2$ (rumenic acid, RA), an isomer of conjugated linoleic acid (CLA) with potentially healthy properties, is distinctive as it is produced naturally in ruminants, from rumen metabolism of dietary PUFA, or from tissue desaturation of $t-11-18: 1$ (vaccenic acid, VA). In addition, it has been demonstrated that VA consumption can increase serum RA in humans (Turpeinen et al., 2002) and milk RA in lactating women (Mosley et al., 2006), and the literature suggests that VA has health benefits beyond those associated with being the only known precursor of RA (Field et al., 2009).

The approach to improve the FA profile in milk from nongrazing dairy ruminants is to add oilseeds or plant oils rich in unsaturated fatty acids (UFA) to the diet. However, this supplementation could also increase the milk content of some FA such as $t-9$ - and $t-10-18: 1$ (Bernard et al., 2009c), which are deemed undesirable for human consumption (Hodgson et al., 1996). Furthermore, Roy et al. (2007) have found that t-10-18:1 has detrimental effects on plasma lipids in lipoprotein metabolism in rabbits.

Extensive research has been conducted in dairy cows to investigate the effect of different plant oils on milk FA profile (Collomb et al., 2004; Bu et al., 2007). Available results point out that the milk FA response to the inclusion of unsaturated plant oils in the diet of dairy goats could be different from that observed in dairy 
cows (Chilliard et al., 2003; Bernard et al., 2009a,b). Furthermore, most of the research has been carried out on high-yielding goat breeds (Chilliard et al., 2003; Chilliard and Ferlay, 2004) or has been focused on a limited number of milk FA with indigenous breeds of goats (Bouattour et al., 2008).

Increasing the milk content of RA and VA through the addition of plant oils to goat diets and decreasing SFA as well as n-6/n-3 ratio could add extra value to dairy products. However, it is important to know not only which vegetable oil promotes the highest increase of those FA but also to gather information on the level of added oil that produces the desired effects. The aim of this work was to study the change of the FA profile in goat milk when increasing amounts of 3 different plant oils were added to the diet.

\section{MATERIALS AND METHODS}

\section{Animals, Housing, and General Management}

The experiments were carried out on the premises of the Animal Production building of the University of Córdoba (Córdoba, Spain), in accordance with the Spanish regulation on experimental animals. The same 12 multiparous Malagueña goats $(70,85$, and 100 DIM at the beginning of experiments 1, 2, and 3 respectively, and $46.6 \pm 3.7 \mathrm{~kg}$ of initial $\mathrm{BW}$ ) were used in each experiment. The animals were in a room at $24 \pm 1^{\circ} \mathrm{C}$ temperature and $16 \mathrm{~h}$ of light. They were placed in individual cages of $1.0 \times 1.4 \mathrm{~m}$ with slatted floor and water and feeding troughs. Before the experiment, all the animals were vaccinated against contagious agalactia, gangrenous mastitis, clostridium enterotoxemia, and hemorrhagic septicemia (Laboratorios Ovejero SA, León, Spain). The goats were machine milked and stripped out by hand once per day at $0830 \mathrm{~h}$. The diet was offered in 2 equal meals at 0930 and $1600 \mathrm{~h}$.

\section{Experimental Design and Diets}

Three experiments were arranged, one per oil tested: linseed oil (LO, experiment 1), high oleic sunflower oil (HOSFO, experiment 2), and regular sunflower oil (RSFO, experiment 3). The design was the same for the 3 experiments (Table 1). It consisted of 4 treatments: no added oil (control treatment, $\mathbf{C}$ diet), and 3 levels of oil addition, $30 \mathrm{~g} / \mathrm{d}$ (low-level treatment, $\mathbf{L}$ diet), $48 \mathrm{~g} / \mathrm{d}$ (medium-level treatment, $\mathbf{M}$ diet), and $66 \mathrm{~g} / \mathrm{d}$ (high-level treatment, $\mathbf{H}$ diet). The same goats were used in each experiment. Within and at the beginning of each experiment, each treatment was allocated

Table 1. Ingredients, chemical composition, and oil FA supply of the experimental diets

\begin{tabular}{|c|c|c|c|c|c|c|c|c|c|c|}
\hline \multirow{2}{*}{ Item } & \multirow{2}{*}{$\begin{array}{c}\text { Control } \\
\operatorname{diet}^{1}\end{array}$} & \multicolumn{9}{|c|}{ Experiment $^{2}$} \\
\hline & & \multicolumn{3}{|c|}{ LO diet } & \multicolumn{3}{|c|}{ HOSFO diet } & \multicolumn{3}{|c|}{ RSFO diet } \\
\hline \multicolumn{11}{|l|}{$\operatorname{Diet}(\mathrm{g} / \mathrm{d})$} \\
\hline Alfalfa hay & 600 & & 600 & & & 600 & & & 600 & \\
\hline Concentrate $^{3}$ & 1,200 & & 1,200 & & & 1,200 & & & 1,200 & \\
\hline $\mathrm{RSFO}^{4}$ & - & - & - & - & - & - & - & 30 & 48 & 66 \\
\hline \multicolumn{11}{|c|}{ Chemical composition } \\
\hline $\mathrm{DM}(\%)$ & 91.2 & 91.1 & 91.5 & 91.9 & 90.8 & 91.4 & 91.2 & 91.4 & 91.2 & 91.0 \\
\hline $\mathrm{CP}(\% \mathrm{DM})$ & 16.7 & 16.3 & 16.3 & 15.9 & 16.2 & 15.9 & 16.0 & 16.3 & 16.2 & 16.0 \\
\hline $\mathrm{NDF}(\% \mathrm{DM})$ & 28.1 & 26.9 & 26.9 & 26.1 & 27.5 & 27.5 & 27.1 & 27.7 & 27.1 & 27.2 \\
\hline $\mathrm{Fat}^{5}(\% \mathrm{DM})$ & 3.1 & 4.9 & 5.7 & 6.8 & 4.6 & 5.4 & 6.7 & 4.7 & 5.5 & 6.6 \\
\hline Ash (\% DM) & 7.4 & 7.3 & 6.6 & 7.1 & 7.4 & 7.5 & 7.2 & 7.5 & 7.2 & 7.3 \\
\hline $18: 3 n-3$ & - & 15.0 & 23.9 & 32.9 & - & - & - & - & - & - \\
\hline
\end{tabular}

${ }^{1}$ Control diet supplied 5.1, 0.8, 6.9, 18.9, and $6.5 \mathrm{~g} / \mathrm{d}$ of 16:0, 18:0, cis-9-18:1, 18:2n-6, and 18:3n-3, respectively, calculated according to INRA (2002). This diet was included in all 3 experiments.

${ }^{2} \mathrm{LO}=$ linseed oil, $\mathrm{HOSFO}=$ high oleic sunflower oil, $\mathrm{RSFO}=$ regular sunflower oil, and $\mathrm{L}=$ low, $\mathrm{M}=$ medium, and $\mathrm{H}=$ high oil supplementation.

${ }^{3}$ Composition (g/kg, as fed): maize, 375.0; barley, 374.9, soybean meal, 200.0, vitamin and mineral premix (Maxi Nutral Ovejas; Nutral SA, Madrid, Spain), 30.0; binder (Exal; Tolsa SA, Madrid, Spain), 20.0; antioxidant (Luctanox; Lucta SA, Barcelona, Spain), 0.1.

${ }^{4}$ The oils were included in the respective concentrate.

${ }^{5}$ Fat by acid hydrolysis. 


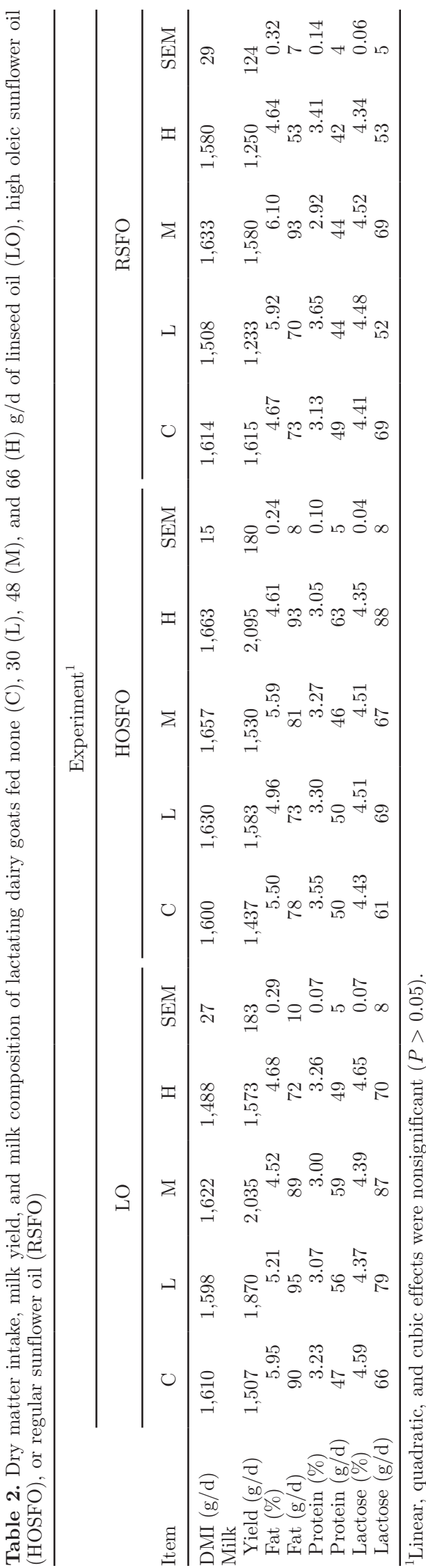

to 3 goats, at random, and lasted $15 \mathrm{~d}$. According to different studies (Chilliard et al., 2007), this time would be enough to get responses of FA in milk fat not different of those obtained with longer periods.

Equal amounts of the same basal diet were used across treatments and experiments (Table 1). It consisted of 33:67 alfalfa hay-pelleted concentrate. To get the aimed oil intakes, convenient amounts of the 3 oils were added to the concentrate mix before pelleting. Pelleted concentrates were kept in plastic bags at $4^{\circ} \mathrm{C}$ until fed to the animals.

\section{Measurements, Sample Collection, and Chemical Analysis}

Voluntary feed intake was recorded daily for each animal. Daily DMI was calculated as the difference between DM in offered feed and orts. The ingredients of the diets were sampled at the beginning of each experiment and stored, as well as the orts, at $-20^{\circ} \mathrm{C}$ until analysis. The procedures described by AOAC (2006) were used to measure DM in feeds and orts (method 930.15), and ash (method 942.05), CP (method 984.13), and fat by acid hydrolysis in feeds (method 954.02). Neutral detergent fiber was measured in feeds by the method described by Van Soest et al. (1991). Samples of the 3 plant oils used were methylated with sodium methoxide/trifluoride, extracted with isooctane, and injected in a gas chromatograph (Agilent $6890 \mathrm{~N}$ Network System; Agilent Technologies Inc., Palo Alto, CA) with autoinjector and fitted with a flame ionization detector. The profile of FA methyl esters (FAME) was determined by split injection (1:50) onto a SupelcoWaxsemicapillary column $(30 \mathrm{~m} \times 0.53 \mathrm{~mm}$ i.d., $1.00-\mu \mathrm{m}$ film thickness; Supelco Inc., Bellefonte, PA) using a programmed temperature method. The initial oven temperature was $175^{\circ} \mathrm{C}$. After $2 \mathrm{~min}$, the oven temperature was raised at $8^{\circ} \mathrm{C} \mathrm{min}{ }^{-1}$ to $235^{\circ} \mathrm{C}$ and then held for $8 \mathrm{~min}$. Helium was the carrier gas and the injector and detector were at $250^{\circ} \mathrm{C}$.

Three samples of milk were taken from each animal at d 15, one for chemical composition (Milko-Scan FT120; Foss Electric A/S, Hillerød, Denmark) and the others for FA analysis. Individual milk yield was recorded in the last $3 \mathrm{~d}$ of each experiment. Daily milk was weighed and expressed on a 24 -h basis.

To analyze FA composition, milk fat was extracted following the procedure described by Luna et al. (2005). Separated lipids were stored in amber vials, blanketed with a stream of $\mathrm{N}_{2}$, and stored at $-20^{\circ} \mathrm{C}$ until analysis. Fatty acid methyl esters were prepared by base-catalyzed methanolysis of the glycerides (ISO-IDF 2002a). Analysis of FAME in hexane was performed on a gas chromatograph (Agilent 6890 N Network System; 
Table 3. Experiment 1: milk FA profile ( $\mathrm{g} / 100 \mathrm{~g}$ of total FA methyl esters) determined by gas chromatography of lactating dairy goats fed none $(\mathrm{C}), 30(\mathrm{~L}), 48(\mathrm{M})$, and $66(\mathrm{H}) \mathrm{g} / \mathrm{d}$ of linseed oil

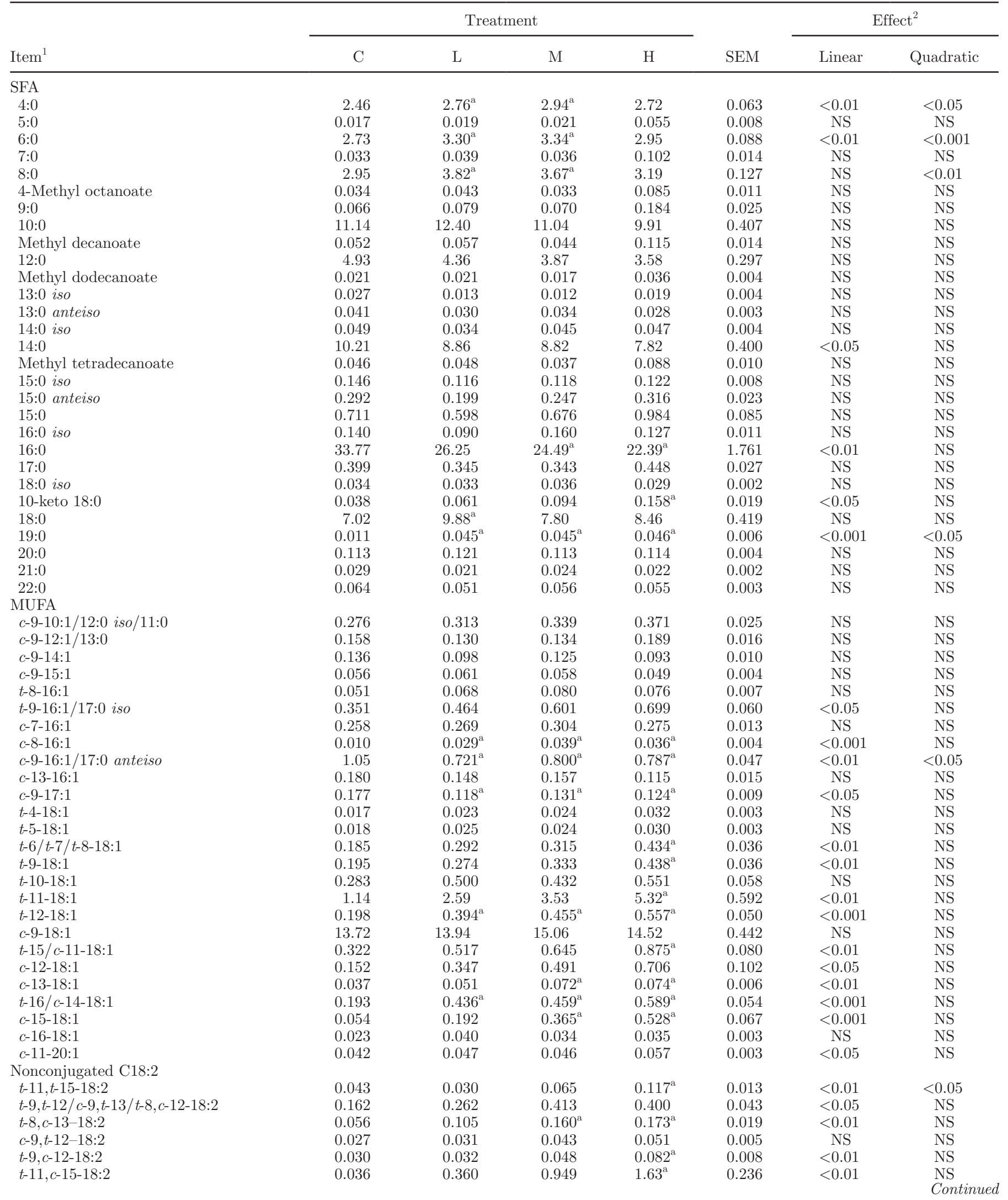


Table 3 (Continued). Experiment 1: milk FA profile (g/100 g of total FA methyl esters) determined by gas chromatography of lactating dairy goats fed none $(\mathrm{C}), 30(\mathrm{~L}), 48(\mathrm{M})$, and $66(\mathrm{H}) \mathrm{g} / \mathrm{d}$ of linseed oil

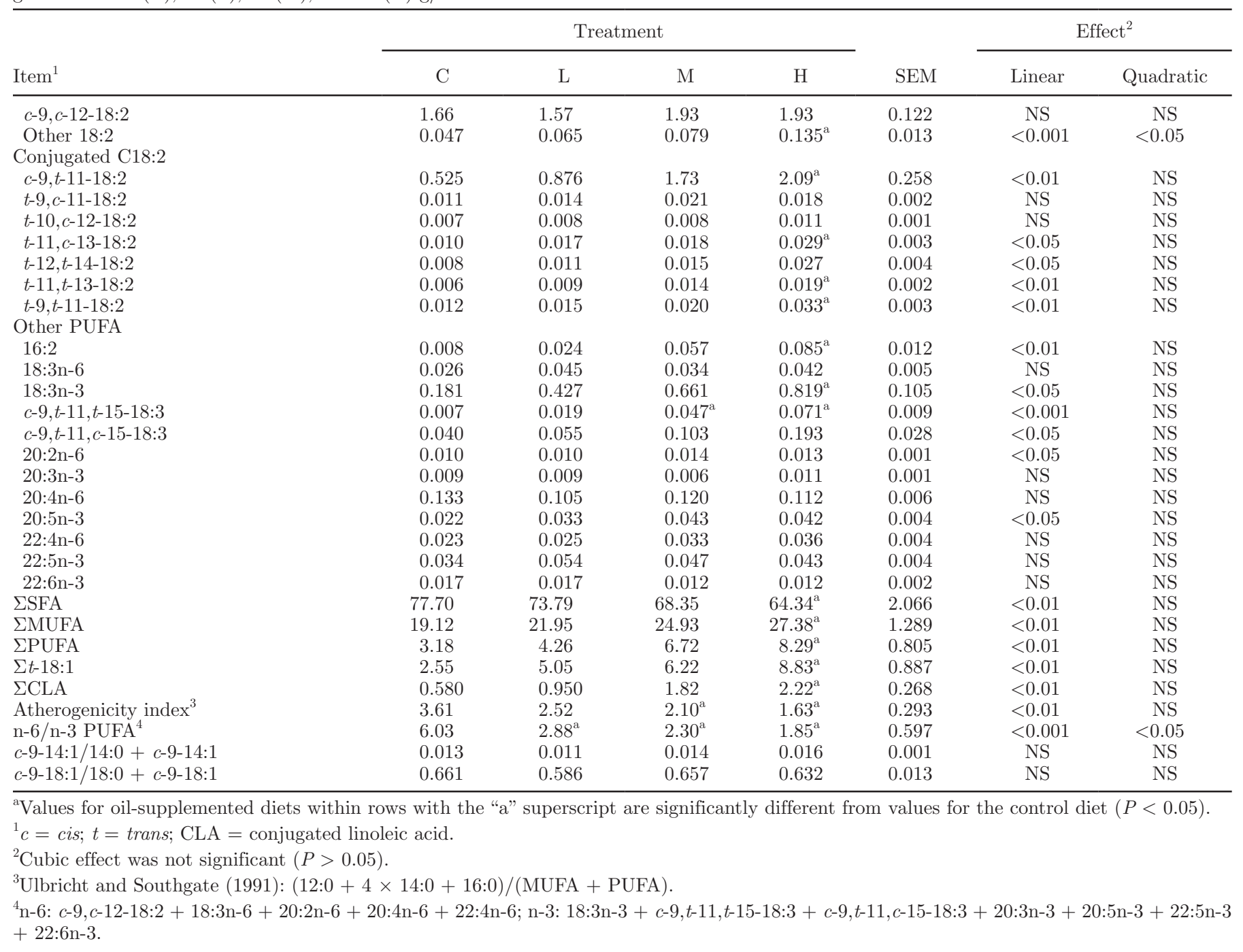

Agilent Technologies Inc.) with autoinjector and fitted with a flame-ionization detector. The FAME profile was determined by split injection (1:100) onto a CP-Sil 88 fused silica capillary column $(100 \mathrm{~m} \times 0.25 \mathrm{~mm}$ i.d., $0.20-\mu \mathrm{m}$ film thickness; Varian Inc., Middelburg, the Netherlands) using a programmed temperature method. The initial oven temperature was $160^{\circ} \mathrm{C}$. After $80 \mathrm{~min}$, the oven temperature was raised at $10^{\circ} \mathrm{C} \mathrm{min}^{-1}$ to $210^{\circ} \mathrm{C}$ and then held for $35 \mathrm{~min}$. Helium was the carrier gas and the injector and detector were at $250^{\circ} \mathrm{C}$.

Quantification of individual FAME was made by reference to a milk fat with a certified composition (CRM 164; European Community Bureau of Reference, Brussels, Belgium) according to the International Organization for Standardization-International Dairy Federation (ISO-IDF, 2002b). Individual isomers of CLA were identified by comparison to standard mixtures distributed by Nu-Chek Prep Inc. (Elysian, MN); GLC-461 from $\mathrm{Nu}$-Chek Prep Inc. was also used to identify other FA.

\section{Statistical Analyses}

Data were analyzed using the GLM procedure of SAS (SAS Institute, 2004). The response to oil levels was investigated through preplanned polynomial contrasts. The model was $Y_{i j}=\mu+T_{i}+\varepsilon_{i j}$, where $Y_{i j}$ is the observation (DMI, milk, fat, protein, lactose, and FAME contents), $\mu$ is the overall mean, $T_{i}$ is the fixed effect of treatment $(i=4)$, and $\varepsilon_{i j}$ is the random residual. Additionally, means from the diets with added oil were compared with the control diet using the Dunnett test. Correlations between the daily intake of plant oils and selected FA were investigated with the SAS CORR procedure. Statistical significance was declared at $P<0.05$. 
Table 4. Experiment 2: milk FA profile ( $\mathrm{g} / 100 \mathrm{~g}$ of total FA methyl esters) determined by gas chromatography of lactating dairy goats fed none (C), $30(\mathrm{~L}), 48(\mathrm{M})$, and $66(\mathrm{H}) \mathrm{g} / \mathrm{d}$ of high oleic sunflower oil

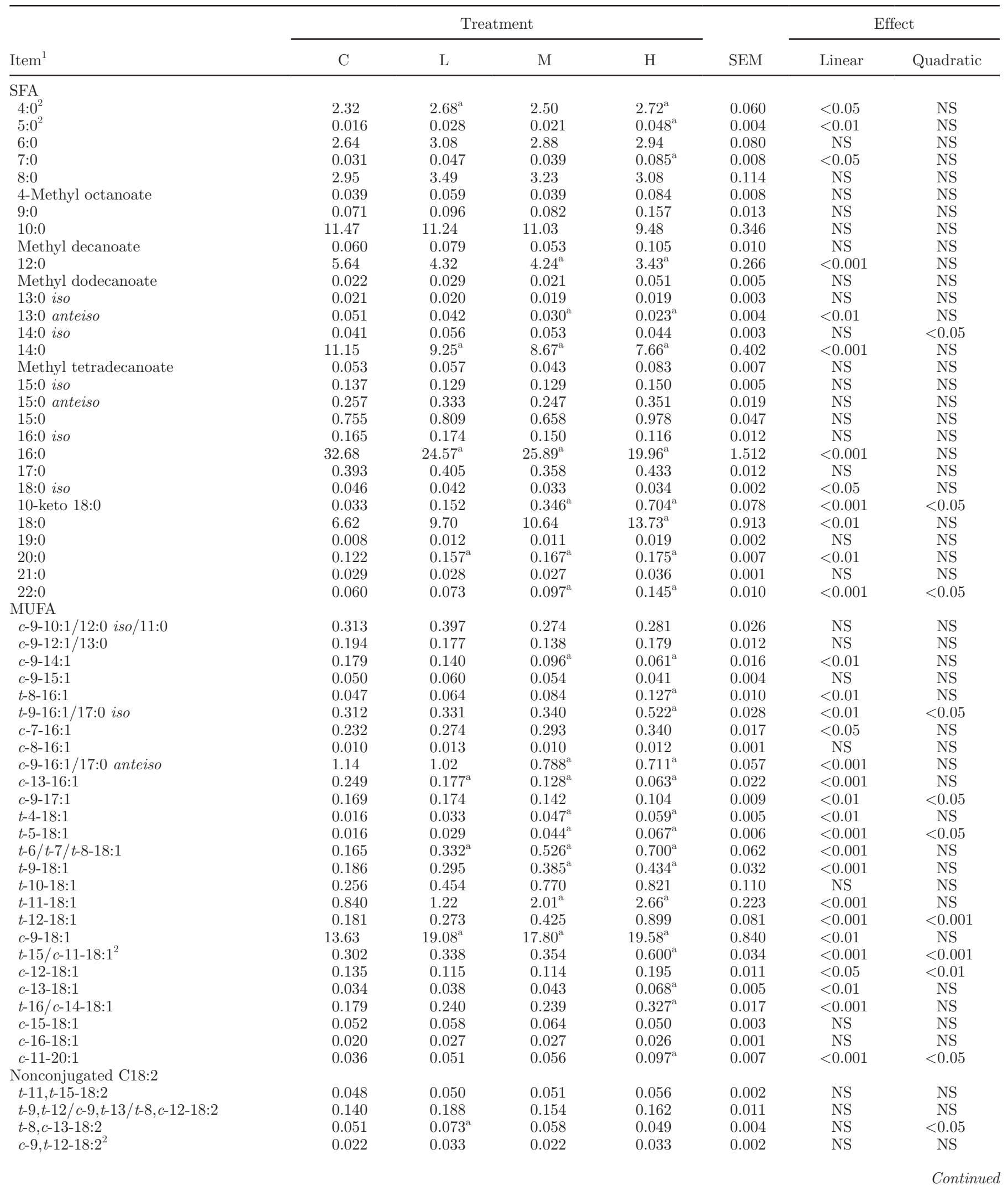


Table 4 (Continued). Experiment 2: milk FA profile (g/100 g of total FA methyl esters) determined by gas chromatography of lactating dairy goats fed none $(\mathrm{C}), 30(\mathrm{~L}), 48(\mathrm{M})$, and $66(\mathrm{H}) \mathrm{g} / \mathrm{d}$ of high oleic sunflower oil

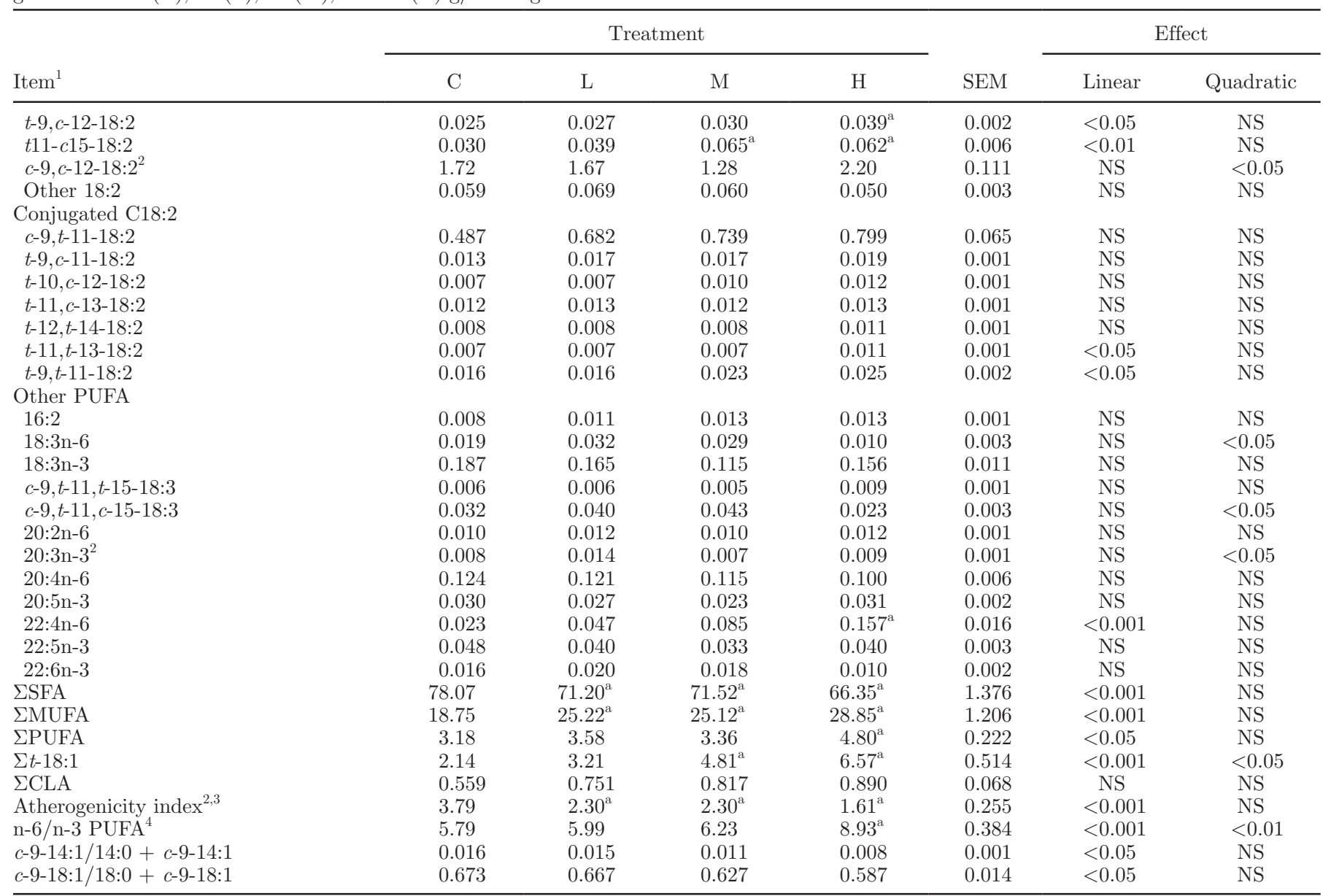

${ }^{a}$ Values for oil-supplemented diets within rows with the "a" superscript are significantly different from values for the control diet $(P<0.05)$.

${ }^{1} c=$ cis, $t=$ trans; CLA $=$ conjugated linoleic acid.

${ }^{2}$ Cubic effect was significant $(P<0.05)$.

${ }^{3}$ Ulbricht and Southgate (1991): $(12: 0+4 \times 14: 0+16: 0) /($ MUFA + PUFA).

${ }^{4} \mathrm{n}-6: c-9, c-12-18: 2+18: 3 \mathrm{n}-6+20: 2 \mathrm{n}-6+20: 4 \mathrm{n}-6+22: 4 \mathrm{n}-6 ; \mathrm{n}-3: 18: 3 \mathrm{n}-3+c-9, t-11, t-15-18: 3+c-9, t-11, c-15-18: 3+20: 3 \mathrm{n}-3+20: 5 \mathrm{n}-3+22: 5 \mathrm{n}-3$ $+22: 6 \mathrm{n}-3$.

\section{RESULTS}

Oleic and linoleic acids were the predominant FA in the HOSFO and RSFO diets, respectively, whereas LO diets showed a more balanced supply of the 3 main FA of plant origin: oleic, linoleic and $\alpha$-linolenic, although the last one was quantitatively the most important (Table 1). Adding oil did not affect intake, milk yield, and fat, protein and lactose contents (Table 2). It can be calculated from intake figures in Table 2 that actual oil intake was close to the aimed targets: 28.1, 44.6, and $61.1 \mathrm{~g} / \mathrm{d} ; 29.3,46.5$, and $63.3 \mathrm{~g} / \mathrm{d}$; and $28.3,44.9$, and $61.1 \mathrm{~g} / \mathrm{d}$ for the $\mathrm{L}, \mathrm{M}$, and $\mathrm{H}$ diets in the LO, HOSFO, and RSFO experiments, respectively.

Tables 3, 4, and 5 show the milk FA profile in the experiments, which included LO, HOSFO, and RSFO, respectively. Table 6 shows Pearson correlation coefficients between daily intake of plant oils and the content of selected FA in milk fat. About 80 different peaks were identified and quantified by GC. Of these FA, 25 did not show any significant linear effect and 58 did not have quadratic effect, whatever the experiment or the treatment was. No cubic effects were found in the LO experiment and only 2 and 5 cubic effects were found in the RSFO and HOSFO experiments, respectively.

Nine milk fat FA showed common linear effects of oil supplementation, whatever the oil was. The content of 14:0 and especially 16:0 in milk fat was negatively affected by the oil supplementation. The effect was greater the higher the level of oil inclusion in all the experimental treatments. On the other hand, lauric acid decreased and stearic acid increased in a linear man- 
Table 5. Experiment 3: milk FA profile (g/100 g of total FA methyl esters) determined by gas chromatography of lactating dairy goats fed none (C), $30(\mathrm{~L}), 48(\mathrm{M})$, and $66(\mathrm{H}) \mathrm{g} / \mathrm{d}$ of regular sunflower oil

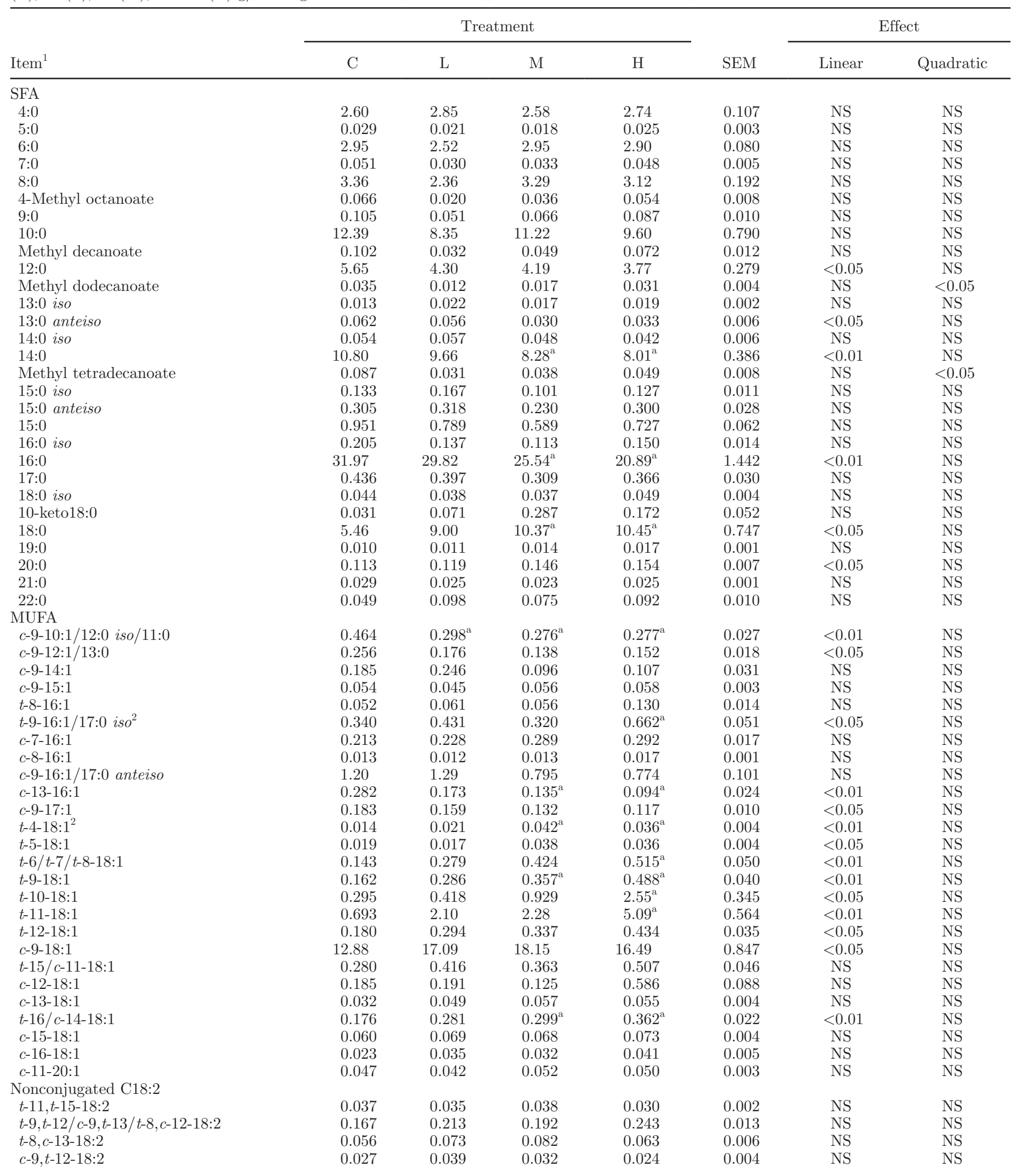


Table 5 (Continued). Experiment 3: milk FA profile (g/100 g of total FA methyl esters) determined by gas chromatography of lactating dairy goats fed none $(\mathrm{C}), 30(\mathrm{~L}), 48(\mathrm{M})$, and $66(\mathrm{H}) \mathrm{g} / \mathrm{d}$ of regular sunflower oil

\begin{tabular}{|c|c|c|c|c|c|c|c|}
\hline Item $^{1}$ & \multicolumn{4}{|c|}{ Treatment } & SEM & \multicolumn{2}{|c|}{ Effect } \\
\hline$t-9, c-12-18: 2$ & 0.032 & 0.033 & 0.041 & 0.049 & 0.004 & NS & NS \\
\hline$c-9, c-12-18: 2$ & 2.04 & 1.73 & 1.47 & 2.89 & 0.245 & NS & NS \\
\hline Other $18: 2$ & 0.050 & 0.057 & 0.043 & 0.046 & 0.004 & NS & NS \\
\hline \multicolumn{8}{|l|}{ Conjugated C18:2 } \\
\hline$t-11, c-13-18: 2$ & 0.012 & 0.015 & 0.013 & 0.010 & 0.001 & NS & NS \\
\hline$t-12, t-14-18: 2$ & 0.007 & 0.013 & 0.011 & 0.008 & 0.002 & NS & NS \\
\hline$t-11, t-13-18: 2$ & 0.006 & 0.008 & 0.009 & 0.006 & 0.001 & NS & NS \\
\hline$t-9, t-11-18: 2$ & 0.015 & 0.022 & 0.018 & 0.022 & 0.002 & NS & NS \\
\hline \multicolumn{8}{|l|}{ Other PUFA } \\
\hline $16: 2$ & 0.005 & 0.009 & 0.011 & 0.013 & 0.001 & $<0.05$ & NS \\
\hline $20: 3 n-3$ & 0.009 & 0.006 & 0.007 & 0.006 & 0.001 & NS & NS \\
\hline $20: 4 n-6$ & 0.127 & 0.128 & 0.113 & 0.116 & 0.004 & NS & NS \\
\hline $20: 5 n-3$ & 0.033 & 0.026 & 0.026 & 0.019 & 0.002 & NS & NS \\
\hline $22: 4 n-6$ & 0.025 & 0.031 & 0.082 & 0.049 & 0.011 & NS & NS \\
\hline $22: 5 n-3$ & 0.050 & 0.047 & 0.034 & 0.038 & 0.004 & NS & NS \\
\hline $22: 6 n-3$ & 0.017 & 0.017 & 0.022 & 0.015 & 0.002 & NS & NS \\
\hline$\Sigma \mathrm{SFA}$ & 78.33 & $71.49^{\mathrm{a}}$ & $70.55^{\mathrm{a}}$ & $64.16^{\mathrm{a}}$ & 1.573 & $<0.001$ & NS \\
\hline$\Sigma M U F A$ & 18.18 & $24.53^{\mathrm{a}}$ & $25.73^{\mathrm{a}}$ & $29.85^{\mathrm{a}}$ & 1.311 & $<0.001$ & NS \\
\hline$\Sigma$ PUFA & 3.50 & 3.98 & 3.72 & $5.99^{\mathrm{a}}$ & 0.376 & $<0.01$ & NS \\
\hline$\Sigma t-18: 1$ & 1.96 & 4.11 & 5.07 & $10.02^{\mathrm{a}}$ & 1.026 & $<0.01$ & NS \\
\hline$\Sigma C L A$ & 0.471 & 1.11 & 0.976 & $1.95^{\mathrm{a}}$ & 0.213 & $<0.01$ & NS \\
\hline Atherogenicity index ${ }^{3}$ & 3.75 & $2.56^{\mathrm{a}}$ & $2.14^{\mathrm{a}}$ & $1.60^{\mathrm{a}}$ & 0.239 & $<0.001$ & NS \\
\hline n-6/n-3 PUFA ${ }^{4}$ & 6.30 & 5.90 & 6.70 & $11.46^{\mathrm{a}}$ & 0.849 & $<0.05$ & $<0.05$ \\
\hline$c-9-14: 1 / 14: 0+c-9-14: 1$ & 0.017 & 0.018 & 0.011 & 0.013 & 0.001 & NS & NS \\
\hline
\end{tabular}

${ }^{a}$ Values for oil-supplemented diets within rows with the "a" superscript are significantly different from values for the control diet $(P<0.05)$.

${ }^{1} c=$ cis, $t=$ trans; CLA $=$ conjugated linoleic acid.

${ }^{2}$ Cubic effect was significant $(P<0.05)$.

${ }^{3}$ Ulbricht and Southgate (1991): $(12: 0+4 \times 14: 0+16: 0) /($ MUFA + PUFA).

${ }^{4} \mathrm{n}-6: c-9, c-12-18: 2+18: 3 \mathrm{n}-6+20: 2 \mathrm{n}-6+20: 4 \mathrm{n}-6+22: 4 \mathrm{n}-6 ; \mathrm{n}-3: 18: 3 \mathrm{n}-3+c-9, t-11, t-15-18: 3+c-9, t-11, c-15-18: 3+20: 3 \mathrm{n}-3+20: 5 \mathrm{n}-3+22: 5 \mathrm{n}-3$ $+22: 6 \mathrm{n}-3$.

ner with the increasing oil addition in the RSFO and HOSFO experiments, but not in the LO experiment.

Oleic acid showed a linear effect of increasing additions of HOSFO but not of RSFO or LO supplementations. Other MUFA also demonstrated linear effects of the supplementation of some but not all the oils (Tables 3,4 , and 5). Vaccenic acid showed a linear increase in all the 3 experiments but this was numerically lower in experiment with HOSFO than in experiments with RSFO and LO. The content of $t-10-18: 1$ was not affected by increasing levels of LO; however, an increasing linear trend was observed with HOSFO and a significant linear effect with RSFO. The lowest levels of $t-10-18: 1$ were measured in LO diets. On the other hand, $t-15-18: 1$ (co-eluted with $c-11-18: 1$ ) showed an increasing response to HOSFO diets and LO diets. The latter produced a positive linear effect in milk fat con- tent of $c-15-18: 1$, which did not appear in milk fat of goats fed HOSFO and RSFO diets.

The CLA isomers did not show a common response to all the 3 oils used in the 3 experiments. Two isomers $(t-11, c-13-18: 2$ and $t-12, t-14-18: 2)$ showed a positive linear effect only with LO diets. Rumenic acid showed a positive linear effect with $\mathrm{LO}$ and RSFO diets. Two other FA, $t-11, t-13-18: 2$ and $t-9, t-11-18: 2$, responded positively to the LO and HOSFO diets, and one ( $t$ 9,c-11-18:2) to the RSFO diets but not to the HOSFO and LO diets. Finally, 18:3n-3, $c-9, t-11, t-15-18: 3, c-9, t-$ 11,c-15-18:3, and 20:5n-3 showed positive linear effects only with the LO diets (Table 3 ).

By classes, the sum of SFA had a common negative linear response to dietary oil inclusion, whereas the sums of MUFA and PUFA responded positively to all of the oil-supplemented diets. The sum of $t-18: 1$ 
Table 6. Significant $(P<0.05)$ Pearson correlation coefficients between the intake of plant oils $(\mathrm{g} / \mathrm{d})$ and the content of selected FA in goat milk ( $\mathrm{g} / 100 \mathrm{~g}$ of total FA methyl esters)

\begin{tabular}{|c|c|c|c|}
\hline \multirow[b]{2}{*}{$\mathrm{FA}^{1}$} & \multicolumn{3}{|c|}{ Oil } \\
\hline & Linseed & $\begin{array}{l}\text { High oleic } \\
\text { sunflower }\end{array}$ & $\begin{array}{l}\text { Regular } \\
\text { sunflower }\end{array}$ \\
\hline $4: 0+6: 0+8: 0+10: 0$ & NS & NS & NS \\
\hline $12: 0+14: 0+16: 0$ & -0.89 & -0.91 & -0.94 \\
\hline $18: 0$ & NS & 0.82 & 0.73 \\
\hline$t-10-18: 1$ & NS & 0.64 & 0.71 \\
\hline$t-11-18: 1$ & 0.92 & 0.91 & 0.79 \\
\hline$c-9-18: 1$ & NS & 0.75 & NS \\
\hline$t-15 / c-11-18: 1$ & 0.90 & 0.76 & NS \\
\hline$c-15-18: 1$ & 0.94 & NS & NS \\
\hline$t-11, t-15-18: 2$ & 0.74 & NS & NS \\
\hline$t-11, c-15-18: 2$ & 0.89 & 0.78 & NS \\
\hline$c-9, c-12-18: 2$ & NS & NS & NS \\
\hline$c-9, t-11-18: 2$ & 0.83 & NS & 0.67 \\
\hline$t-9, c-11-18: 2$ & NS & 0.63 & 0.68 \\
\hline$t-10, c-12-18: 2$ & NS & NS & NS \\
\hline$t-11, c-13-18: 2$ & 0.81 & NS & NS \\
\hline$t-12, t-14-18: 2$ & 0.68 & NS & NS \\
\hline$t-11, t-13-18: 2$ & 0.83 & NS & NS \\
\hline$t-9, t-11-18: 2$ & 0.82 & 0.70 & NS \\
\hline $18: 3 n-3$ & 0.82 & NS & NS \\
\hline$c-9, t-11, t-15-18: 3$ & 0.92 & NS & NS \\
\hline$c-9, t-11, c-15-18: 3$ & 0.71 & NS & NS \\
\hline$\Sigma$ CLA & 0.84 & NS & 0.67 \\
\hline
\end{tabular}

${ }^{1} t=$ trans $; c=$ cis $;$ CLA $=$ conjugated linoleic acid.

FA increased linearly with oil supplementation in all of the experiments. In contrast, the sum of CLA isomers showed a positive linear response to LO and RSFO but not to HOSFO supplementation.

The atherogenicity index had a common decreasing response to oil supplementation. In the LO experiment, the addition of any amount of linseed oil to the basal diet (low in $\alpha$-linolenic acid; Table 1) produced a sharp decrease in the n-6/n-3 PUFA ratio. On the contrary, the major increase in this ratio was observed in the RSFO diet with the highest level of added oil (Table $5)$. The n-6/n-3 PUFA ratio in milk fat decreased by about $70 \%$ (from 6.03 to 1.85) with the highest level of LO supplementation (Table 3), whereas the most remarkable increase (from 6.30 to 11.46) was observed with diet $\mathrm{H}$ of the RSFO treatment (Table 5).

\section{DISCUSSION}

When feeding diets supplemented with plant oils to dairy goats, normally no appreciable differences in milk production and protein content are obtained, but usually some increases in fat content are produced (Chilliard et al., 2003, 2007). No differences were found in milk yield and fat, protein, and lactose content in this work, which was not designed to find such differences (due to the low number of goats used per group, high individual variations in fat content, and the lack of use of pre-experimental covariates) but to find out differences in the milk fat FA profile.
A large number of reports carried out in dairy ruminants show that adding fat sources rich in UFA to diets decreases the content of short- and medium-chain SFA in milk fat. According to Chilliard and Ferlay (2004), the reason for this response may have a double origin. First, a decreased production of VFA in the rumen due to dietary UFA would decrease the amount of substrate for FA synthesis in the mammary cell. Second, the long-chain FA taken up by the mammary gland could inhibit enzymatic activities in the pathways of FA synthesis in the mammary cell. In this work, it appears that no shortage of substrate existed for the synthesis of short- and medium-chain SFA in the mammary gland of goats eating the oil-supplemented diets because most odd- and branched-chain FA did not show variation with the addition of increasing amount of oils to the control diet (Tables 3, 4, and 5), which can be considered as an index of lack of severe negative effects of the added oils on the rumen microbial activity (Harfoot and Hazlewood, 1997; Vlaeminck et al., 2006). In contrast, Bernard et al. (2009c) observed negative effects of added oils (RSFO and LO) on odd and branched FA content in milk fat. This could be only partly attributed to the dose of added oil $(130 \mathrm{~g} / \mathrm{d})$. In comparison, in the current research, the intake of oil with the highest level of added oil was slightly lower $(0.70$ or 0.98 on a DMI or milk fat yield basis, respectively) than that reported by Bernard et al. (2009c).

Recently, Bernard et al. (2009a) considered that the inhibition of major lipogenic genes or enzymes may not 

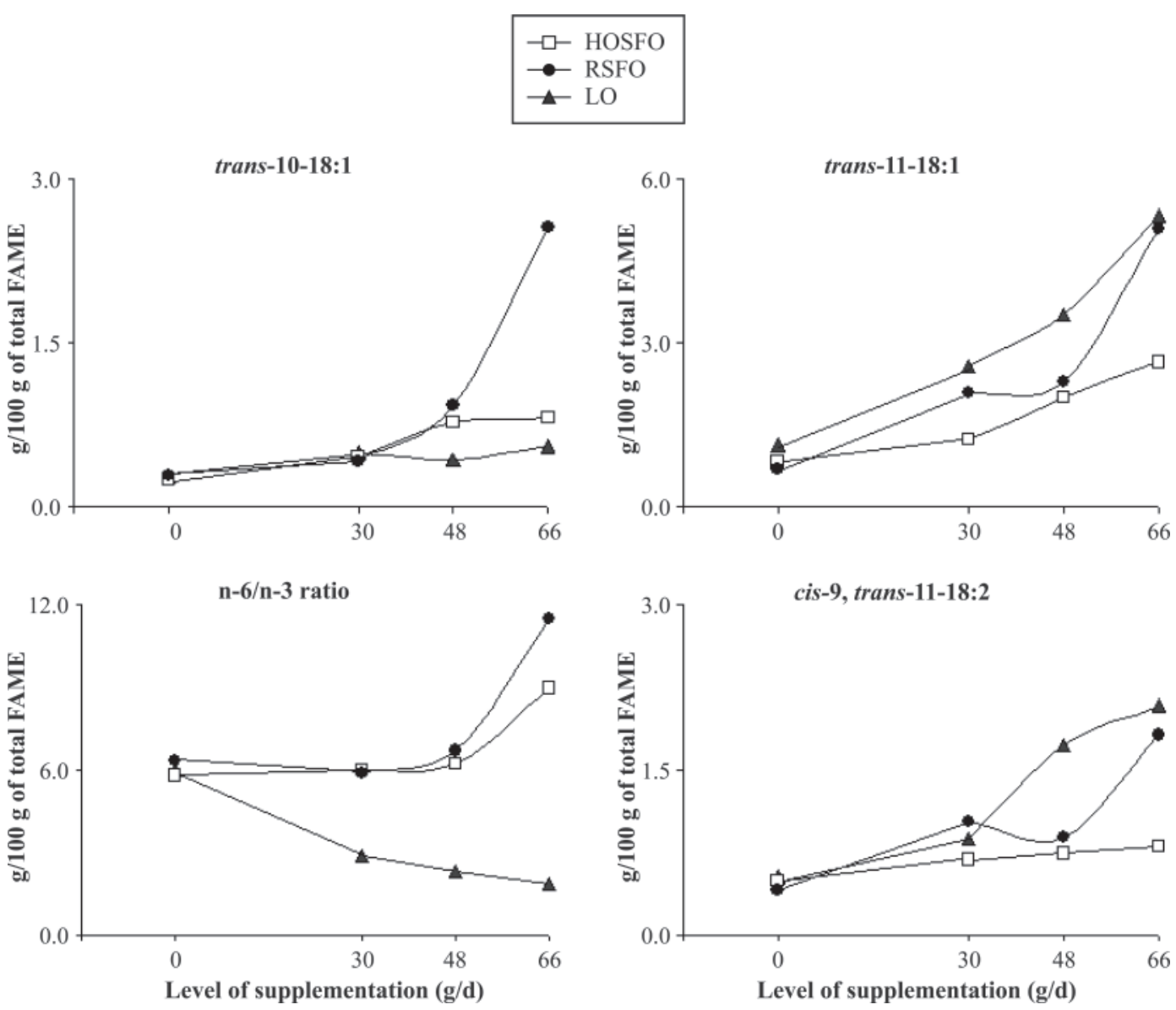

Figure 1. Trans-10-18:1, trans-11-18:1, and cis-9,trans-11-18:2 contents and n-6/n-3 ratio in milk fat of goats fed none, 30, 48, and $66 \mathrm{~g} / \mathrm{d}$ of linseed oil (LO), high oleic sunflower oil (HOSFO), or regular sunflower oil (RSFO). FAME = FA methyl esters.

be the main cause (other than decreased substrate) of the negative response of short- and medium-chain SFA to plant oils and that other metabolic pathways or genes can be involved. The cause of the significant decrease observed in the milk fat concentration of 12:0, except with LO, 14:0, and 16:0, and its negative correlation to daily oil intake (Table 6) in all 3 experiments of this work, could be the inhibiting effect of the increasing supply of long-chain FA to the mammary gland on the ratio of acetyl-CoA carboxylase to FA synthetase activities. Results of in vitro research cited by Bauman and Davis (1974) show that altering the ratio of acetyl-CoA carboxylase to FA synthetase activities in the mammary cell shifts the pattern of FA synthesized toward the shorter chain types when the ratio decreases. The same effect is obtained when the ratio of acetyl-CoA to malonyl-CoA increases. Results obtained by Bernard et al. (2009a) point in that direction: the ratio of acetyl-CoA carboxylase to FA synthetase activities decreased in their work by 32 and $40 \%$ without reduction of the secretion (and content) of $\mathrm{FA}$ from 4:0 to 8:0 in goat milk fat when diets including RSFO or LO, respectively, were fed instead of a control diet. That could also be the case in the current work, as the shorter FA (4:0 to 8:0) showed no negative, even positive, responses to oil supplementation (Tables 3,4 , and $5)$. Capric acid was in an intermediate position as was not significantly affected but, at least in the HOSFO experiment, showed a negative linear trend. The sum of 4:0 to 10:0 content in milk fat was uncorrelated to daily oil intake (Table 6).

The fact that in this work the milk fat content of 4:0, 6:0, and 8:0 was not decreased by dietary oil supplementation, and that the generally observed negative effects on short- and medium-chain SFA started clearly only from 12:0 upwards, except with LO, is a frequent observation in goat experiments (Okine et al., 2003; Nudda et al., 2006; Bouattour et al., 2008). However in other studies (Bernard et al., 2005, 2009c; Ollier et al., 2009) a decrease in milk 10:0, and even 8:0 (and less frequently 6:0) has also been documented.

In this work, most 18:0 in milk fat would come from a complete rumen biohydrogenation $(\mathbf{B H})$ of dietary UFA because 18:0 ingested with the control and oil- 
supplemented diets (Table 1) was much lower than 18:0 yield in milk fat (calculated from Table 2 and Tables 3 , 4 , and 5). Any 18-carbon UFA in the rumen may be the source of 18:0 through $\mathrm{BH}$. As a result, a significant linear effect on 18:0 content was observed in the HOSFO and RSFO diets. In contrast, the lack of linear effect of LO diets would indicate that they did not favor a complete rumen $\mathrm{BH}$ of the UFA, raising the contents of $\alpha$-linolenic acid and its intermediates in milk fat. With diets based on grass hay and concentrates, Bernard et al. (2009c) did not find differences of 18:0 content in milk fat between LO- and sunflower oil-added diets, although they did find such differences with diets based on maize silage and concentrates.

The $c-9-18: 1$ in milk fat may have a double origin. It may come from preformed $c-9-18: 1$ taken up by the mammary gland or it may be formed in the udder by $\Delta^{9}$ desaturation of 18:0. Enjalbert et al. (1998) observed in cows that desaturation of 18:0 in the mammary gland to $c-9-18: 1$ averaged about half of the uptake. In the HOSFO experiment, the milk fat content of $c-9-18: 1$ with the $\mathrm{L}$ diet increased when compared with that of the $\mathrm{C}$ diet to a level not different than that showed by the greater HOSFO intakes with the $\mathrm{M}$ and $\mathrm{H}$ diets. It seemed logical to find higher contents of oleic acid in milk fat of goats fed greater amounts of oleic acid. However, oleic acid is preferably converted into a wide variety of $t$-MUFA (Mosley et al., 2002; GómezCortés et al., 2008b). Furthermore, an inhibition of the stearoyl-CoA desaturase (SCD) by the increased availability of PUFA and $t$-FA in the mammary gland was suggested by Chilliard and Ferlay (2004). In goats, Bernard et al. (2005) reported lower values of SCD activity when supplementing a control diet with $3.6 \%$ of HOSFO. In our study, the ratio of $c-9-18: 1$ to $18: 0$ plus c-9-18:1, decreased as the supplementation of HOSFO increased (Table 4), which suggests that desaturation in the HOSFO experiment did not keep pace with the increased supply of stearic acid to the udder. The linear decrease in the ratio $c-9-14: 1$ to $14: 0$ plus $c-9-14: 1$ would support this contention (Table 4). No changes in the ratio $c-9-14: 1$ to $14: 0$ plus $c-9-14: 1$ were observed in the RSFO or LO experiments, although the ratio $c-9-18: 1$ to $18: 0$ plus $c-9-18: 1$ tended to decrease in the RSFO experiment (Tables 3 and 5). Moreover, the daily intake of LO was correlated neither with the content of 18:0 nor with $c-9-18: 1$ in milk fat (Table 6 ). The lack of response of $c-9-18: 1$ in milk fat to LO supplementation is consistent with dairy goat data of Chilliard et al. (2003, 2007) and Chilliard and Ferlay (2004), although some published research shows positive responses of $c-9-18: 1$ to linseeds or linseed oil supplementation (Bernard et al., 2005, 2009a; Nudda et al., 2006), but not that of Nudda et al. (2007) who reported no increases in $c-9$ -
18:1 content in milk fat when supplementing diets with extruded linseed cake.

The clear positive response of most of the $t$-MUFA to all the different supplements could be interpreted as an incomplete $\mathrm{BH}$ of dietary UFA in the rumen, leaving many MUFA and PUFA intermediates along the $\mathrm{BH}$ pathways. The content of VA in milk fat increased faster with oil supplementation in the RSFO and LO experiments than in the HOSFO experiment, the values obtained with the $\mathrm{H}$ diets of those 2 experiments being twice as high as that observed with the $\mathrm{H}$ diet in the HOSFO experiment (Figure 1). Vaccenic acid is the main intermediate product in the $\mathrm{BH}$ pathways of $18: 2$ and 18:3n-3 (Bauman et al., 1999). In contrast, VA is not the predominant $\mathrm{BH}$ product of $c-9-18: 1$ and, as a result of its isomerization, a wide spectrum of $t$-MUFA are obtained (Mosley et al., 2002; AbuGhazaleh et al., 2005; Gómez-Cortés et al., 2008b). In the present work, the VA content in milk fat was in accordance with the last 2 statements, as the VA content in milk fat with the RSFO and LO diets was much higher than with the HOSFO diets.

The isomer $t$-10-18:1 increased more with the $\mathrm{H}$ diet in the RSFO experiment that in the corresponding diet of the HOSFO experiment (Figure 1). Gómez-Cortés et al. (2008a,b) reported a similar pattern (i.e., higher content of $t-10-18: 1$ in milk fat of ewes fed a linoleic acid-rich diet instead of an oleic acid-rich one). In contrast, Bodas et al. (2010) found similar contents of $t-10-18: 1$ when feeding dairy ewes diets rich in oleic or linoleic acids, probably due to their basal diet having a high forage:concentrate ratio. It is well known that rations rich in concentrate favor the shift in the 18:2 rumen BH pathways toward the formation of higher levels of $t-10-18: 1$ in milk fat (Shingfield and Griinari, 2007). On the other hand, the $\mathrm{BH}$ of $18: 3 \mathrm{n}-3$ is less prone to promote $t-10-18: 1$ formation than that of linoleic acid (AbuGhazaleh and Jacobson, 2007) and consistent with this, the content of $t-10-18: 1$ did not increase in LO-fed goats, which would be positive from a nutritional point of view. Larger increases in t-10-18:1 milk fat content in response to RSFO in comparison with LO supplementation were also reported by Bernard et al. (2009c) using diets similar in starch and NDF content to those assayed in the present trial.

Total CLA isomers were positively correlated with daily LO and RSFO intake but not with HOSFO intake (Table 6). This is not unexpected, as $c-9-18: 1$ was the main FA supplied by HOSFO, and oleic acid is not converted to CLA isomers during rumen $\mathrm{BH}$. Of the 5 CLA isomers responding to LO in this work, only RA had a positive response to RSFO. A similar result was also reported by Bernard et al. (2009c) who used a daily amount of supplemental oil higher than the high- 
est level assayed in the present work. Rumenic acid, which mainly originates in the udder by desaturation of VA (Bauman et al., 1999; Bernard et al., 2010), increased in the milk fat of goats fed LO and RSFO diets to levels slightly higher than the (nonsignificant) responses obtained with HOSFO diets (Figure 1).

In the $\mathrm{LO}$ experiment, an increase in the $\mathrm{BH}$ intermediates of 18:3n-3 was observed in milk from goats fed the supplemented diets. The group $c-9, t-11, c-15-18: 3$; $t-11, c-15-18: 2$; and $c-15-18: 1$ belongs to a well-known BH pathway (Harfoot and Hazlewood, 1997); the group $c-9, t-11, t-15-18: 3 ; \quad t-11, t-15-18: 2$; and $t-15-18: 1$ corresponds to an alternative pathway recently postulated by Gómez-Cortés et al. (2009), working with dairy ewes, and the CLA isomer $t-11, c-13-18: 2$ was postulated from a dairy cow study by Kraft et al. (2003) and Collomb et al. (2004) as a probable intermediate of an unknown BH pathway of 18:3n-3. Luna et al. (2008) and Bernard et al. (2009c) found the isomer $t-15-18: 1$ and the isomer $t-11, t-15-18: 2$, respectively, in milk fat of LO-fed goats. The CLA isomer $t-11, c-13-18: 2$ was reported by Luna et al. (2008) and Bernard et al. (2009a,c) in milk of goats fed whole linseed and LO, respectively. All of these isomers involved in the $\mathrm{BH}$ of $18: 3 \mathrm{n}-3$ showed positive correlations with the daily intake of LO (Table $6)$.

As a consequence of the negative linear effect of oil addition on the content of 12:0, 14:0, and 16:0, and the increased content of UFA in milk fat, the atherogenicity index decreased in the milk of all 3 experiments (Tables 3,4 , and 5). This was also observed in dairy ewes by Bodas et al. (2010). The decreased ratio of n-6 to n-3 PUFA in milk fat from goats fed LO-supplemented diets (Figure 1) was expected, as LO was the only oil used in this work with significant content of 18:3n-3. This effect is commonly reported when LO or linseeds are included in the diet of cows, goats, and ewes (Bu et al., 2007; Chilliard et al., 2007; Bodas et al., 2010). The observed increase of n- 6 to n-3 PUFA in milk fat from goats fed RSFO-supplemented diets agrees with the results reported from research conducted with ewes by Bodas et al. (2010) who also observed a larger increase in n-6 to n-3 PUFA in milk fat when the supplemented oil was richer in 18:2 (sunflower oil) than in $c-9-18: 1$ (olive oil).

\section{CONCLUSIONS}

An effect observed in this work was that the responses in the proportions of milk fat FA to dietary increases of the 3 oils tested, when present, were linear for several FA. Considering that the consumption of $\mathrm{RA}$ is beneficial for human health and that VA is a source of RA, adding LO and RSFO to goat diets seems favorable because it resulted in milk richer in both FA. In contrast, supplementation with HOSFO did not significantly modify milk RA, whereas VA increased only by about half of the increases obtained with the other 2 oils. On the other hand, the content of $t-10-18: 1$, whose intake could be considered a risk factor for cardiovascular disease in humans, did not increase in milk fat with increasing LO dietary supplementation. Besides that, the decreased ratio of n-6 to n-3 FA in milk fat from diets supplemented with LO also contributes to make this oil, especially at the highest level, the most favorable alternative compared with HOSFO or RSFO.

\section{ACKNOWLEDGMENTS}

This work was financed by the Ministerio de Ciencia e Innovación (MICINN; AGL2008-04805 and Consolider Ingenio 2010 Programme; FUN-C-FOOD CSD2007063) and the Comunidad Autónoma de Madrid (Spain; 2009-AGR-1469). The authors thank A. Jiménez Secilla and B. Garfia Catalán of Laboratorio Agropecuario Regional of Córdoba (Spain) for their help with milk composition analysis, I. Andújar-Ramírez (University of Cordoba, Spain) and M. V. Rodríguez-Pino (CSIC, Madrid, Spain) for their technical assistance in processing milk samples, and J. J. Pérez-Hernández (University of Cordoba, Spain) for his assistance in the animal feeding and management.

\section{REFERENCES}

AbuGhazaleh, A. A., and B. N. Jacobson. 2007. The effect of $\mathrm{pH}$ and polyunsaturated $\mathrm{C} 18$ fatty acid source on the production of vaccenic acid and conjugated linoleic acids in ruminal cultures incubated with docosahexaenoic acid. Anim. Feed Sci. Technol. 136:11-22.

AbuGhazaleh, A. A., M. B. Riley, E. E. Thies, and T. C. Jenkins. 2005. Dilution rate and $\mathrm{pH}$ effects on the conversion of oleic acid to trans C18:1 positional isomers in continuous culture. J. Dairy Sci. 88:4334-4341.

AOAC. 2006. Official Methods of Analysis of the Association of Official Agricultural Chemists. 18th ed. 1st rev. AOAC Int., Gaithersburg, MD.

Bauman, D. E., L. H. Baumgard, B. A. Corl, and J. M. Griinari. 1999. Biosynthesis of conjugated linoleic acid in ruminants. Proc. Am. Soc. Anim. Sci. Annu. Mtg. 1999. Accessed Feb. 28, 2010. http:// www.asas.org/jas/symposia/proceedings/0937.pdf.

Bauman, D. E., and C. L. Davis. 1974. Biosynthesis of milk fat. Pages 31-75 in Lactation: A Comprehensive Treatise. Volume 2. B. L. Larson and V. R. Smith, ed. Academic Press, New York, NY.

Bernard, L., M. Bonnet, C. Leroux, K. J. Shingfield, and Y. Chilliard. 2009a. Effect of sunflower-seed oil and linseed oil on tissue lipid metabolism, gene expression, and milk fatty acid secretion in Alpine goats fed maize silage-based diets. J. Dairy Sci. 92:60836094.

Bernard, L., C. Leroux, Y. Faulconnier, D. Durand, K. J. Shingfield, and Y. Chilliard. 2009b. Effect of sunflower-seed oil or linseed oil on milk fatty acid secretion and lipogenic gene expression in goats fed hay-based diets. J. Dairy Res. 76:241-248.

Bernard, L., J. Mouriot, J. Rouel, F. Glasser, P. Capitan, E. PujosGuillot, J. M. Chardigny, and Y. Chilliard. 2010. Effects of fish oil and starch added to a diet containing sunflower-seed oil on 
dairy goat performance, milk fatty acid composition and in vivo $\Delta$ 9-desaturation of $\left.{ }^{13} \mathrm{C}\right]$ vaccenic acid. Br. J. Nutr. 104:346-354.

Bernard, L., J. Rouel, C. Leroux, A. Ferlay, Y. Faulconnier, P. Legrand, and Y. Chilliard. 2005. Mammary lipid metabolism and milk fatty acid secretion in alpine goats fed plant lipids. J. Dairy Sci. 88:1478-1489.

Bernard, L., K. J. Shingfield, J. Rouel, A. Ferlay, and Y. Chilliard. 2009c. Effect of plant oils in the diet on performance and milk fatty acid composition in goats fed diets based on grass hay or maize silage. Br. J. Nutr. 101:213-224.

Bodas, R., T. Manso, A. R. Mantecón, M. Juárez, M. A. de la Fuente, and P. Gómez-Cortés. 2010. Comparison of the fatty acid profiles in cheeses from ewes fed diets supplemented with different plant oils. J. Agric. Food Chem. 58:10493-10502.

Bouattour, M. A., R. Casals, E. Albanell, X. Such, and G. Caja. 2008. Feeding soybean oil to dairy goats increases conjugated linoleic acid in milk. J. Dairy Sci. 91:2399-2407.

Bu, D. P., J. Q. Wang, T. R. Dhiman, and S. J. Liu. 2007. Effectiveness of oils rich in linoleic and linolenic acids to enhance conjugated linoleic acid in milk from dairy cows. J. Dairy Sci. 90:998-1007.

Chilliard, Y., and A. Ferlay. 2004. Dietary lipids and forages interactions on cow and goat milk fatty acid composition and sensory properties. Reprod. Nutr. Dev. 44:467-492.

Chilliard, Y., A. Ferlay, J. Rouel, and G. Lamberet. 2003. A review of nutritional and physiological factors affecting goat milk lipid synthesis and lipolysis. J. Dairy Sci. 86:1751-1770.

Chilliard, Y., F. Glasser, A. Ferlay, L. Bernard, J. Rouel, and M. Doreau. 2007. Diet, rumen biohydrogenation and nutritional quality of cow and goat milk fat. Eur. J. Lipid Sci. Technol. 109:828 855

Collomb, M., A. Schmid, R. Sieber, D. Wechsler, and E.-L. Ryhänen. 2006. Conjugated linoleic acids in milk fat: Variation and physiological effects. Int. Dairy J. 16:1347-1361.

Collomb, M., R. Sieber, and U. Bütikofer. 2004. CLA isomers in milk fat from cows fed diets with high levels of unsaturated fatty acids. Lipids 39:355-364.

Enjalbert, F., M. C. Nicot, C. Bayourthe, and R. Moncoulon. 1998. Duodenal infusions of palmitic, stearic or oleic acids differently affect mammary gland metabolism of fatty acids in lactating dairy cows. J. Nutr. 128:1525-1532.

Field, C. J., H. H. Blewett, S. Proctor, and D. Vine. 2009. Human health benefits of vaccenic acid. Appl. Physiol. Nutr. Metab. 34:979-991.

Givens, D. I., K. E. Kliem, and R. A. Gibbs. 2006. The role of meat as a source of n-3 polyunsaturated fatty acids in the human diet. Meat Sci. 74:209-218.

Gómez-Cortés, P., P. Frutos, A. R. Mantecón, M. Juárez, M. A. de la Fuente, and G. Hervás. 2008a. Milk production, conjugated linoleic acid content, and in vitro ruminal fermentation in response to high levels of soybean oil in dairy ewe diet. J. Dairy Sci. 91:1560-1569.

Gómez-Cortés, P., P. Frutos, A. R. Mantecón, M. Juárez, M. A. de la Fuente, and G. Hervás. 2008b. Addition of olive oil to dairy ewe diets: Effect on milk fatty acid profile and animal performance. J. Dairy Sci. 91:3119-3127.

Gómez-Cortés, P., C. Tyburczy, J. T. Brenna, M. Juárez, and M. A. de la Fuente. 2009. Characterization of cis-9 trans-11 trans-15 C18:3 in milk fat by GC and covalent adduct chemical ionization tandem MS. J. Lipid Res. 50:2412-2420.

Harfoot, C. G., and G. P. Hazlewood. 1997. Lipid metabolism in the rumen. Pages 382-426 in The Rumen Microbial Ecosystem. P. N. Hobson, ed. Blackie Academic \& Professional, London, UK.

Hodgson, J. M., M. L. Wahlqvist, J. A. Boxall, and N. D. Balazs. 1996. Platelet trans fatty acids in relation to angiographically assessed coronary artery disease. Atherosclerosis 120:147-154.

INRA (Institut National de la Recherche Agronomique). 2002. Tables de Composition et de Valeur Nutritive des Matières Premières Destinées aux Animaux D'élevage. Institut National de la Recherche Agronomique, Paris, France.
ISO-IDF (International Organization for Standardization-International Dairy Federation). 2002a. Milk Fat-Preparation of Fatty Acid Methyl Esters. International Standard ISO 15884-IDF 182:2002. International Dairy Federation, Brussels, Belgium.

ISO-IDF (International Organization for Standardization-International Dairy Federation). 2002b. Milk Fat-Determination of the Fatty Acid Composition By Gas-Liquid Chromatography. International Standard ISO 15885-IDF 184: 2002. International Dairy Federation, Brussels, Belgium.

Kraft, J., M. Collomb, P. Möckel, R. Sieber, and G. Jahreis. 2003. Differences in CLA isomer distribution of cow's milk lipids. Lipids 38:657-664.

Luna, P., A. Bach, M. Juárez, and M. A. de la Fuente. 2008. Effect of a diet enriched in whole linseed and sunflower oil on goat milk fatty acid composition and conjugated linoleic acid isomer profile. J. Dairy Sci. 91:20-28.

Luna, P., M. Juárez, and M. A. de la Fuente. 2005. Validation of a rapid milk fat separation method to determine the fatty acid profile by gas chromatography. J. Dairy Sci. 88:3377-3381.

Mosley, E. E., M. K. McGuire, J. E. Williams, and M. A. McGuire. 2006. Cis-9, trans-11 conjugated linoleic acid is synthesized from vaccenic acid in lactating women. J. Nutr. 136:2297-2301.

Mosley, E. E., G. L. Powell, M. B. Riley, and T. C. Jenkins. 2002 Microbial biohydrogenation of oleic acid to trans isomers in vitro. J. Lipid Res. 43:290-296.

Nudda, A., G. Battacone, S. Fancellu, G. A. Carboni, and G. A. Pulina. 2007. The use of linseed and cottonseed to change the fatty acid profile in early lactation dairy goats. Pages 49-53 in Advanced Nutrition and Feeding Strategies to Improve Sheep and Goat Production. A. Priolo, L. Biondi, H. Ben Salem, and P. Morand-Fehr, ed. CIHEAM-IAMZ, Zaragoza, Spain.

Nudda, A., G. Battacone, M. G. Usai, S. Fancellu, and G. Pulina. 2006. Supplementation with extruded linseed cake affects concentrations of conjugated linoleic acid and vaccenic in goat milk. J. Dairy Sci. 89:277-282.

Okine, E. K., L. A. Goonewardene, Z. Mir, P. Mir, Z. Wang, and P. S. Chanmugam. 2003. Influence of canola oil on the fatty acid profile in goats' milk. Can. J. Anim. Sci. 83:323-325.

Ollier, S., C. Leroux, A. de la Foye, L. Bernard, J. Rouel, and Y. Chilliard. 2009. Whole intact rapeseeds or sunflower oil in highforage or high-concentrate diets affects milk yield, milk composition, and mammary gene expression profile in goats. J. Dairy Sci. 92:5544-5560

Roy, A., J.-M. Chardigny, D. Bauchart, A. Ferlay, S. Lorentz, D. Durand, D. Gruffat, Y. Falconnier, J.-L. Sébédio, and Y. Chilliard. 2007. Butters rich either in trans-10-C18:1 or in trans-11-C18:1 plus cis-9, trans-11 CLA differentially affect plasma lipids and aortic fatty streak in experimental atherosclerosis in rabbits. Animal $1: 467-476$.

SAS Institute. 2004. SAS/STAT 9.1 User's Guide. SAS Institute Inc., Cary, NC

Shingfield, K. J., and J. M. Griinari. 2007. Role of biohydrogenation intermediates in milk fat depression. Eur. J. Lipid Sci. Technol. 109:799-816.

Turpeinen, A. M., M. Mutanen, A. Aro, I. Salminen, S. Basu, D. L. Palmquist, and J. M. Griinari. 2002. Bioconversion of vaccenic acid to conjugated linoleic acid in humans. Am. J. Clin. Nutr. $76: 504-510$.

Ulbricht, T. L. V., and D. A. T. Southgate. 1991. Coronary heart disease: Seven dietary factors. Lancet 338:985-992.

Van Soest, P. J., J. B. Robertson, and A. Lewis. 1991. Methods for dietary fiber, neutral detergent fiber and nonstarch polysaccharides in relation to animal nutrition. J. Dairy Sci. 74:3583-3597.

Vlaeminck, B., V. Fievez, S. Tamminga, R. J. Dewhurst, A. van Vuuren, D. De Brabander, and D. Demeyer. 2006. Milk odd- and branched-chain fatty acids in relation to the rumen fermentation pattern. J. Dairy Sci. 89:3954-3964. 